\title{
The Genetic Structure of Nilaparvata lugens (Stal.) in Java Populations
}

\author{
Ruth Martha Winnie', Rika Raffiudin ${ }^{2 *}$, I Nyoman Widiarta ${ }^{3}$, Aunu Rauf1 $^{1}$ \\ 'Department of Plant Protection, Faculty of Agriculture, Bogor Agriculture of University, Bogor, Indonesia \\ ${ }^{2}$ Department of Biology, Faculty of Mathematics and Natural Sciences, Bogor Agriculture of University, Bogor, Indonesia \\ ${ }^{3}$ Indonesian Agency for Agricultural Research and Development, Ministry of Agriculture, Bogor, Indonesia
}

\section{ARTICLE INFO}

Article history:

Received October 28, 2018

Received in revised form July 30, 2020

Accepted August 8, 2020

KEYWORDS:

Nilaparvata lugens, migration,

genetic structure,

mitochondrial marker,

microsatellite marker

\begin{abstract}
The brown planthopper Nilaparvata lugens (Stal.) causes hopperburn in the rice field. The wing macropterous adults of this insect have capability for long distance flight. We aimed to analyze the genetic structure of six $N$. lugens populations in Java inferred from the combined COI-COII mitochondrial and ten loci of microsatellites markers. This study revealed low levels of nucleotides and high levels of haplotype diversity of the planthopper. The demographic test might indicate the genetic bottleneck history of $N$. lugens population in Java. The genetic diversity analyzed by using microsatellite markers also showed high levels of heterozygosity $(\mathrm{Ho}>\mathrm{He})$ that indicated an isolated-breaking effect in the six populations in Java. Moreover, we found a homogenous genetic structure of $N$. lugens based on pairwise fixation indices (Fst) analyzes that appears to be maintained by high levels of gene flow and showed no correlation between genetic and geographical distance. Importantly, these studies also support accurate information of widely distributed and genetically intermixed among $N$. lugens across Asia populations. Thus, our results support the theory of long-distance migration among $N$. lugens populations. The genetic structure information of $N$. lugens in Java could support regional management, such as the new controlling strategies based on forecasting systems.
\end{abstract}

\section{Introduction}

Nilaparvata lugens (Hemiptera: Delphacidae) is an important insect planthopper of the rice ecosystem in three regions of Asia, i.e. South, East, and Southeast (IRRI 2009). The large number of $N$. lugens can destroy crops, which the condition called hopperburn. The $N$. lugens population is showed susceptible rice varieties and wing form response (Iwanaga et al. 1987). Imago of $N$. lugens has two forms of wings, i.e. bracypterous (short wings) and macroptereous (long wings). The long wings form is triggered by high number of individual in the population, which causes long-distance movement behavior to survive their generations (Denno and Roderick 1990; Denno et al. 1991).

The movement of $N$. lugens in South, East, and Southeast Asia (not including Indonesia) has been investigated by using meteorological and molecular

\footnotetext{
* Corresponding Author

E-mail Address: rika.raffiudin@apps.ipb.ac.id
}

approaches. The meteorological approach showed that the population of $N$. lugens has long-distance migration from Vietnam to China and Japan (Sogawa 1992; Otuka et al. 2008). The molecular approaches, i.e. mitochondrial and microsatellite markers were used to analyze the genetic structure of $N$. lugens. The mitochondrial sequences were analyzed by using cytochrome oxidase I (COI) and COII of $N$. lugens from 31 locations and indicated lack of genetic structure among Asian populations, except southern Philippines and Papua New Guinea (Matsumoto et al. 2013). Microsatellite marker was used to analyze the movement of this insect based on 30 polymorphic from two populations of $N$. lugens in China. However, this microsatellite marker is not clear to reveal the $N$. lugens movement pattern yet, because the numbers of the samples are low (Jing et al., 2012).

The spatial distribution of $N$. lugens was investigated at five study sites in West Java (Indonesia), i.e. Cirebon, Indramayu, Jatisari, Karawang, and Subang. The result of this method revealed the movement among those 
areas, however, could not show the movement pattern (Kusmayadi et al. 1990; Sawada et al. 1992, 1993). Therefore, the potential approach, i.e. genetic structure of $N$. lugens in Java has been challenged to elucidate this insect movement. The objective of this study was to analyze the genetic structure of $N$. lugens populations in Java (Indonesia) using molecular approach. This study is the first genetic structure data of $N$. lugens populations in Java (Indonesia) that inferred from mitochondrial (combined of COI and COII genes) and microsatellite markers. This study could reveal the migration among $N$. lugens populations in Java and provide an ecological foundation for developing a better pest management strategy.

\section{Materials and Methods}

\subsection{Insect Collection}

Samples of $N$. lugens macropterous imago were collected from six rice fields in Java, i.e. Lebak, Bogor, Karawang, Boyolali, Pemalang, and Lamongan. Thirty of $N$. lugens were collected from each location and were used for DNA extraction.

\subsection{DNA Extraction and Amplification}

Thirty individuals from each location were used for DNA source from the thorax of $N$. lugens by using a Genomic DNA mini kit for tissue (Geneaid). Those were used to amplify the mitochondrial and microsatellite DNA.

Mitochondrial DNA amplifications used forward primer NLCOIF10: 5’AGAT-TCTGACTTTTACCCCCATC'3 and reverse primer NLCOIR8:5'CTATTGGAGGATTAACA GGTGTA'3 for COI gene and forward primer NLCOIIF1: 5' TCTAATATGGCAGAATAGTGTA'3 and reverse primer NLCOIIR1: 5'CTATTGGAGGATTAACAGGTGTA'3. The primers of $\mathrm{COI}$ and COII genes were designed based on N. lugens mitochondrial genome (Zhang et al. 2013). The amplification of this mitochondrial marker were performed in 30 cycles: denaturation at $95^{\circ} \mathrm{C}$ for 1 min, annealing at $55^{\circ} \mathrm{C}$ for $30 \mathrm{sec}$, and extension at $72^{\circ} \mathrm{C}$ for $45 \mathrm{sec}$. Total of 72 amplicon of COI and COII genes were sequenced by using same primer pairs as in the amplifications.

Microsatellite DNA amplifications were selected from ten polymorphic microsatellite loci based on Jing et al. (2012) of the N. lugens in China and were amplified using fluorescently labeled primers. The PCR cycling program was $94^{\circ} \mathrm{C}(5 \mathrm{~min})$, followed by 35 cycles of $94^{\circ} \mathrm{C}(15 \mathrm{sec})$, and $72^{\circ} \mathrm{C}(30 \mathrm{sec})$, with a final elongation step of $72^{\circ} \mathrm{C}(10 \mathrm{~min})$. We genotyped about 81 of $N$. lugens in a Genescan facilities Applied Biosystems Genetic Analyzer and interpreted using the GeneMapper ${ }^{\circledR}$ v 4.0 analysis software (Applied Biosystems).

\subsection{Statistical Analysis}

Genetic diversity. The total 32 combined of COI-COII mitochondrial sequences of $N$. lugens were analyzed by using CLUSTALX(1.83)(Thompson et al. 1997) and MEGA 6 (Tamura et al. 2013). Genetic diversity of combined COI-COII sequences were conducted by using DnaSP version 5 (Rozas et al. 2003) to estimate the number of polymorphic sites (S), nucleotide diversity ( $\pi$ ), and haplotype diversity (h) of the $N$. lugens.

The microsatellite data were assembled using the GENEMAPPER software and determined for stuttering, large allele dropout and null alleles using MICROCHECKER version 2.2.3 (van Oosterhout et al. 2004). The genetic diversity was analyzed by using MICROSATELLITE ANALYZER(MSA) version 4.05 (Dieringer and Schlötterer 2003) to test the allele frequency, the number of alleles, observed and expected heterozygosity. The tests for deviations from Hardy-Weinberg equilibrium for each population were performed by using GENPOP version 4.0.11 (Raymond and Rousset 1995).

Demographic analysis. This method was conducted to test the neutrality of each population that examined from combined COI-COII sequences. The demographic history of N. lugens populations in Java were analyzed by the Tajima's D and Fu's F statistics. The distributions of pairwise differences between individual sequences were analyzed using mismatch distribution analysis. Demographic analysis was performed using the program ARLEQUIN version 3.5 (Excoffier and Lischer 2010).

Population structure. The COI-COII genes and the microsatellites DNA were investigated using the pairwise fixation indices (FST) approach implemented in the program ARLEQUIN version 3.5. It was used to analyze the genetic structure based on the pairwise FST values between each pair of the six populations. The values of fixation indices among populations within populations $\left(\mathrm{F}_{\mathrm{ST}}\right)$ were compared with different group numbers within each dataset. Unrooted neighborjoining (NJ) trees were constructed based on FST values of microsatellite by using TreeFit (Kalinowski 2009).

Isolation by distance. The pairwise $\mathrm{F}_{\mathrm{ST}}$ values based on the COI-COII genes and the microsatellites DNA were analyzed to establish whether any isolation-bydistance effect occurred, matrices of genetic distance 
data $\left[\mathrm{F}_{\mathrm{ST}} /\left(1-\mathrm{F}_{\mathrm{ST}}\right)\right]$ and the logarithms of geographical distance (ln $\mathrm{Km}$ ) between all the sampling sites were constructed. The In Km value was conducted by using Geographic Distance Matrix Generator version 1.2.3 (Ersts 2006). These matrices were analyzed to determine the degree of correlation using a Mantel test (Mantel 1967) implemented in the software IBD version 1.53 (Bohonak 2002).

Gene flow. The gene flows among populations were examined using Migrate version 3.2.16 (Beerli and Felsenstein 2001). This analysis was conducted to test the asymmetric dispersal between populations, the mutation-scaled population size $(\Theta=N e \mu$, where $\mu$ is the mutation rate per site per generation) and the mutation-scaled migration rate $(\mathrm{M}=m / \mu$, where $\mathrm{m}$ is the migration rate) were calculated using Bayesian. The effective number of migrants entering and leaving each population per generation $x N e m$ is $\Theta M(x$ is a multiplier that depends on the ploidy and inheritance of the data, and here, $x$ is one for mitochondrial DNA).

\section{Results}

\subsection{The Nilaparvata lugens Collection}

Six locations of $N$. lugens in Java sampled and identified as a central of rice field in Indonesia and those are not isolated area. All rice sampling locations were cultivated the Ciherang rice variety, except Karawang rice field that used Mikongga variety. In this field study, we observed $N$. lugens outbreak status in the rice field area in Bgr and Lmg. For genetic structure analysis, we conducted in total 36 individual of combined COI-COII sequences and 81 individual of microsatellites marker (Table 1).

\subsection{Genetic Diversity}

Genetic diversity analysis based on combined of COI and COII genes showed highly haplotype diversity $(\mathrm{h}=$ $0.600-0.933)$ but low genetic diversity $(\pi=0.00000-$ 0.0025 ). The demographic history, Tajima's D calculation showed no significantly positive in the four populations ( $D=0.00000$ - 0.70767; p>0.005), except Pml and Lmg populations showed no significantly negative. Similar tendencies with Tajima's D calculation were found based on Fu's F statistics (Table 2), thus might indicate of genetic bottleneck history of this insect based on the parameters of genetic diversity and demographic history.

Based on the microsatellite loci we found the number of alleles was ranged from 71 to 83 from the six populations of $N$. lugens. The expected heterozygosity
(He) was ranged from 0.768 to 0.901 while the observed heterozygosity (Ho) was ranged from 0.949 to 1.000 . Furthermore, test of Hardy-Weinberg equilibrium resulted no significant deviation $\left(P_{\mathrm{HWE}}>0.05\right)$ among the ten loci in $N$. lugens populations (Table 3 ), thus $N$. lugens population is in HWE expectation. It means that the deviations from $\mathrm{HWE}$ (when $\mathrm{Ho}>\mathrm{He}$ ) were due to the heterozygote excess. This heterozygosity analysis showed high levels of variation in general might result from an isolated-breaking.

\subsection{Population Structure}

Pairwise fixation index $\left(\mathrm{F}_{\mathrm{ST}}\right)$ values were calculated for all combinations of six locations based on two type molecular marker. The combined COI-COII marker showed no significantly high values $(0.37500$; $\mathrm{p}>0.05$ ) in Bogor population (Table 4). It showed that differentiation population with other population. Whereas, the pairwise $\mathrm{F}_{\mathrm{ST}}$ based on microsatellites marker showed no significantly low values (less than 0.02000; $>0.05$ ) (Table 5). Furthermore, the pairwise $\mathrm{F}_{\mathrm{ST}}$ values of microsatellite data were used to construct the unrooted $\mathrm{NJ}$ tree that revealed no genetic structure among $N$. lugens populations across Java (Figure 1). Moreover, both of genetic markers showed the negative value of pairwise indicated lack of genetic structure (exclude Bogor population by using mitochondria sequences).

\subsection{Isolation by Distance}

The Mantel test results for two type molecular marker showed high r-value (for 10000 randomizations), i.e. 1) $0.0231(\mathrm{P}=0.916)$ based on combined COI-COII genes (Figure 2) and 2). $0.0494(\mathrm{P}=0.801)$ based on microsatellite marker (Figure 3 ). Those are indicating no isolation-by-distance among $N$. lugens populations in Java. Furthermore, it was supported by scatter plot analysis that showed no correlation between genetic and geographical distance among the 15 populations pairs.

\subsection{Gene Flow}

The unidirectional estimates of gene flow $(M)$ ranged from $0.0(\mathrm{Krw} \rightarrow \mathrm{Pml}$ ) to $597.4(\mathrm{Krw} \rightarrow \mathrm{Lmg}$ ) that conducted by using the mitochondrial marker. The estimates of $M$ analysis between each pair of the six populations showed that high gene flow values. Although, a small amount of three pairs of population showed low gene flow, i.e.: Lbk $\rightarrow$ Lmg, Krw $\rightarrow$ Pml, and Byl $\rightarrow$ Lmg (Table 6). 
Table 1. Collection data of the N. lugens populations that used in this study

\begin{tabular}{|c|c|c|c|c|c|}
\hline \multirow[t]{2}{*}{ Population } & \multirow[t]{2}{*}{ Location } & \multirow[t]{2}{*}{ Date } & \multirow[t]{2}{*}{ Latitude, longitude } & \multicolumn{2}{|c|}{ Total of individual } \\
\hline & & & & $\begin{array}{l}\text { COI-COII } \\
\text { mitochondrial }\end{array}$ & $\begin{array}{l}10 \text { loci } \\
\text { microsatellite }\end{array}$ \\
\hline$\overline{\mathrm{Lbk}}$ & $\begin{array}{l}\text { Lebak, } \\
\text { Banten }\end{array}$ & June 8' 2014 & $06^{\circ} 20.189^{\prime \prime} S, 106^{\circ} 05^{\prime} 465^{\prime \prime} \mathrm{N}$ & 6 & 13 \\
\hline Bgr & $\begin{array}{l}\text { Bogor, } \\
\text { West Java }\end{array}$ & March 10 and 11' 2014 & $06^{\circ} 25^{\prime} 872 " \mathrm{~S}, 109^{\circ} 55^{\prime} 359^{\prime \prime} \mathrm{N}$ & 6 & 14 \\
\hline Krw & $\begin{array}{l}\text { Karawang, } \\
\text { West Java }\end{array}$ & April 19-21’ 2014 & $06^{\circ} 05^{\prime} 256^{\prime \prime S}, 107^{\circ} 55^{\prime} 322^{\prime \prime N}$ & 6 & 14 \\
\hline Byl & $\begin{array}{l}\text { Boyolali, } \\
\text { Central Java }\end{array}$ & April 9-13’ 2014 & $07^{\circ} 32^{\prime} 736^{\prime \prime S}, 110^{\circ} 43^{\prime} 026^{\prime \prime} \mathrm{N}$ & 6 & 14 \\
\hline Pml & $\begin{array}{l}\text { Pemalang, } \\
\text { Central Java }\end{array}$ & June 17’ 2014 & $06^{\circ} 53.104^{\prime} \mathrm{S}, 109^{\circ} 27^{\prime} 654^{\prime \prime} \mathrm{N}$ & 6 & 13 \\
\hline \multirow[t]{2}{*}{ Lmg } & $\begin{array}{l}\text { Lamongan, } \\
\text { East Java }\end{array}$ & March 21-30’ 2014 & $07^{\circ} 05^{\prime} 769^{\prime \prime S}, 112^{\circ} 16^{\prime} 628^{\prime \prime} \mathrm{N}$ & 6 & 13 \\
\hline & & & Total & 36 & 81 \\
\hline
\end{tabular}

Table 2. Parameters of genetic diversity and demographic analysis of $N$. lugens lugens based on combined COI and COII genes

\begin{tabular}{lccccr}
\hline Population & $S$ & $\pi$ & $h$ & $D(p)$ & \multicolumn{1}{c}{$F s(p)$} \\
\hline Lbk & 7 & 0.0024 & 0.0024 & 0.0024 & $0.31383(0.51100)$ \\
Bgr & 0 & 0.0000 & 0.0000 & 0.0000 & $0.00000(1.00000)$ \\
Krw & 7 & 0.0025 & 0.0025 & 0.0025 & $0.42629(0.55300)$ \\
Pml & 8 & 0.0022 & 0.0022 & 0.0022 & $-1.37181(0.10000)$ \\
Byl & 5 & 0.0019 & 0.0019 & 0.0019 & $1.41962(0.78500)$ \\
Lmg & 8 & 0.0025 & 0.0025 & 0.0025 & $-1.12062(0.13500)$ \\
\hline Total & 48 & & & & \\
\hline
\end{tabular}

Number of polymorphic sites $(S)$, Nucleotide diversity $(\pi)$, Haplotype diversity $(h)$, Tajima's D $(D)$, Fu's F statistics $(F s)$, Code of population refers to Table 1

Table 3. Summary statistic showing number of alleles and mean of heterozygosity of $N$. lugens lugens from 10 loci microsatellite

\begin{tabular}{lcllr}
\hline Population & No. of alleles & Ho & He & $P_{\text {HWE }}$ \\
Lbk & 72 & 0.949 & 0.770 & 0.785 \\
Bgr & 79 & 1.000 & 0.768 & 0.643 \\
Krw & 83 & 0.984 & 0.887 & 0.667 \\
Pml & 71 & 0.981 & 0.901 & 0.807 \\
Byl & 78 & 0.990 & 0.868 & 0.674 \\
Lmg & 83 & 1.000 & 0.799 & 0.660 \\
\hline
\end{tabular}

Total refers to Table 1

Table 4. Pairwise fixation index $\left(\mathrm{F}_{S T}\right)$ values of $N$. lugens based on the combined COI and COII mitochondrial sequences

\begin{tabular}{lllllll}
\hline Population & Lbk & Bgr & Krw & Pml & Byl & Lmg \\
\hline Lbk & 0 & & & & & \\
Bgr & 0.14545 & 0 & 0 & & & \\
Krw & -0.07778 & 0.37500 & 0.00357 & 0 & & \\
Pml & -0.10204 & 0.04444 & -0.06531 & -0.09091 & 0 & 0.12174 \\
Byl & -0.14545 & 0.17778 & -0.04211 & -0.10400 & -0.1200 \\
Lmg & -0.15200 & 0.10909 & &
\end{tabular}

Code of population refers to Table 1 
Table 5. Pairwise fixation index $\left(\mathrm{F}_{\mathrm{ST}}\right)$ values of $N$. lugens based on ten loci microsatellites

\begin{tabular}{|c|c|c|c|c|c|c|}
\hline Population & Lbk & Bgr & Krw & Pml & Byl & Lmg \\
\hline bbk & 0 & & & & & \\
\hline Bgr & 0.00635 & 0 & & & & \\
\hline Krw & -0.00410 & -0.01268 & 0 & & & \\
\hline Pml & 0.01662 & 0.00258 & -0.02107 & 0 & & \\
\hline Byl & -0.00108 & -0.00364 & -0.02241 & -0.00812 & 0 & \\
\hline Lmg & 0.00350 & 0.01523 & 0.00070 & -0.00308 & -0.00498 & 0 \\
\hline
\end{tabular}

Code of population refers to Table 1

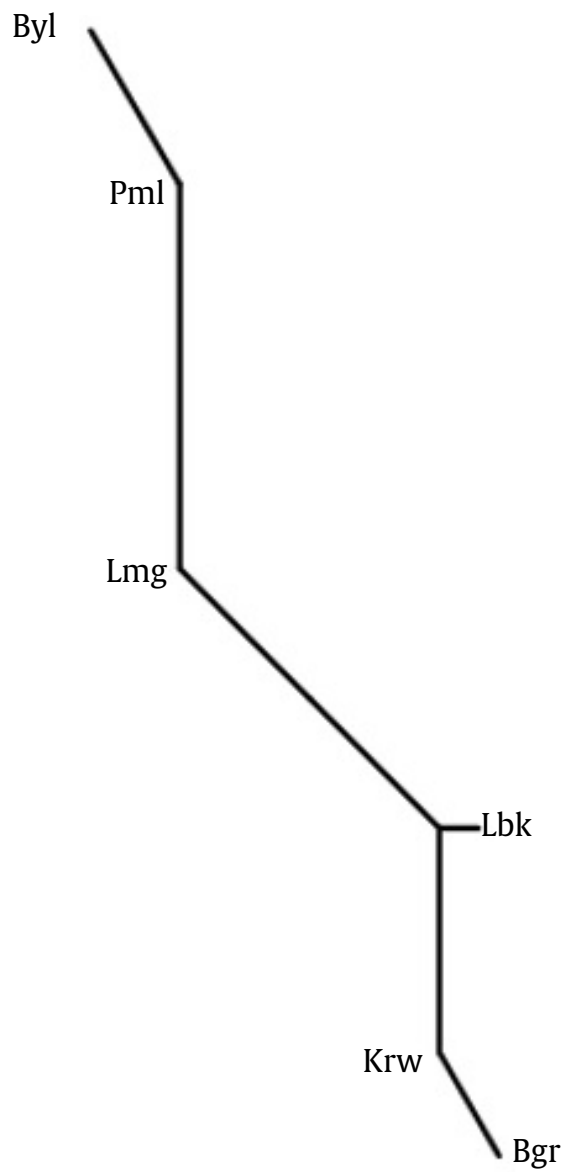

Figure 1. Unrooted NJ trees of six populations N. lugens in this study based on FST value of microsatellite

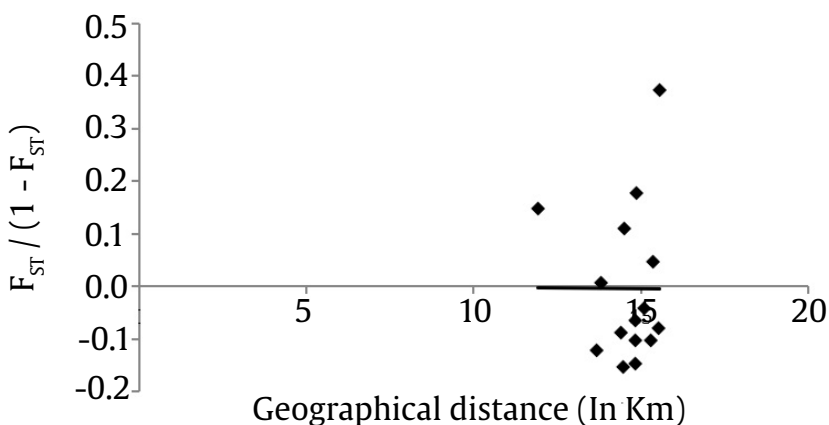

Figure 2. Scatter plot of genetic distance vs. geographical distance for pairwise population comparisons ( $\mathrm{r}$ $=0.0231, \mathrm{P}=0.916,10000$ randomizations), based on combined COI-COII mitochondrial sequences of $N$. lugens

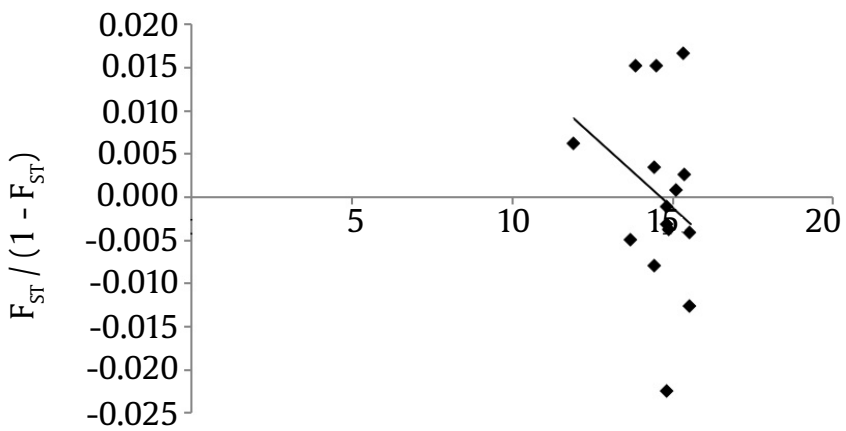

Figure 3. Scatter plot of genetic distance vs. geographical distance for pairwise population comparisons ( $r=0.0494, P=0.801,10000$ randomizations), based on ten microsatellite loci of $N$. lugens

Table 6. Estimates of gene flow $(M)$ among six $N$. lugens populations based on combined COI-COII genes

\begin{tabular}{lllllrrrr}
\hline Pop., $i$ & $\Theta i$ & Lbk $\rightarrow i$ & Bgr $>i$ & Krw $\rightarrow i$ & Pml $>i$ & Byl $->i$ & Lmg $->i$ & Total $i$ \\
\hline Lbk & 0.00446 & - & 498.7 & 496.6 & 493.0 & 497.2 & 6.2 & $1,991.7$ \\
Bgr & 0.05008 & 514.9 & - & 507.5 & 489.1 & 492.9 & 485.0 & $1,974.5$ \\
Krw & 0.04941 & 497.7 & 350.1 & - & 509.2 & 500.9 & 545.2 & $1,905.4$ \\
Pml & 0.00287 & 502.9 & 502.9 & 0.0 & - & 500.4 & 0.1 & $1,003.4$ \\
Byl & 0.04881 & 507.2 & 498.2 & 489.2 & 33.5 & - & 13.6 & $1,034.5$ \\
Lmg & 0.04940 & 4.2 & 491.0 & 597.4 & 513.3 & 8.5 & - & $1,610.2$
\end{tabular}

Ө: mutation-scaled population size, which is effective population size $\times$ mutation rate per site per generation, M: mutation-scaled immigration rate, which is the immigration rate divided by the mutation rate 


\section{Discussion}

The genetic diversity of $N$. lugens in Java based on the combined COI and COI sequences, showed low levels nucleotide diversity $(\pi)$ and high levels haplotype diversity (h). Mean of heterozygosity value also showed high level of variations by using microsatellite marker. Furthermore, the demographic analyze showed in selective neutrality ( $p>0.05$ ) with a stable effective population size and thus implied genetic bottleneck history in Java population. This genetic diversity based of two types of molecular marker indicated that the $N$. lugens population in Java had reached stability in gene frequency (Sun et al. 2015) that was also analyzed in Laodelphax striatelluss (Hemiptera: Delphacidae) from China. The L. striatelluss has been revealed the bottleneck history and this conclusion was supported by both genetic diversity and demographic analysis by using mitochondrial and microsatellite markers.

The high haplotype diversity might due to the adaptation of this insect to crop cultivated (Wei et al. 2013). A high-level haplotype condition of $N$. lugens also found in Plutella xylostella (Lepidoptera: Plutellidae) from China by using microsatellite marker. The key factor leading to high haplotype diversity might be indicated by both of the high level of selection pressure of insecticide and local climate. Furthermore, Matsumoto et al. (2013) also explained that the level of insecticide resistance is related to the genetic structure of populations reflects gene flow over a longer time scale. The pairwise fixation indices $\left(\mathrm{F}_{\mathrm{ST}}\right)$ results indeed suggest no genetic structure in $N$. lugens populations across Java.

Moreover, we suggest that lack of genetic structure information of this study to be relatively similar between the outbreak and non-outbreak events. All the sampling areas consisted of two-rice field status, i.e. outbreak (Bgr and Lmg) and non-outbreak status (Lbk, Krw, Byl, and Pml), and all sampling locations are not isolated areas. It showed in Locusta migratoria (Orthoptera: Acrididae) as cosmopolitan insect that suggested the outbreak and non-outbreak events is not influence with the genetic structure of locust (Chapuis et al. 2008) by using microsatellite marker. Furthermore, this condition has been considered mostly the typical of migratory of this insect.

In the present study, the Mantel test indicated unparallel between genetic and geographical distance among the six populations of $N$. lugens in
Java. It revealed no isolation-by-distance, as in $P$. xylostella (Lepidoptera: Plutellidae) in China revealed by mitochondrial and microsatellite markers (Wei et al. 2013). Furthermore, the gene flow approaches indicates that the $N$. lugens populations migrates in Java. The gene flow of most pairs populations are consistent and indicate high level values. it avoids genetic drift from causing local genetic differentiation, which the species with typical of migratory abilities generally show correspondingly high levels of gene flow (Slatkin 1987). These results could be indicated the great movement abilities with the genetic mixing that occurred among $N$. lugens in Java populations. A similar condition also showed in N. lugens among Asia populations by using mitochondrial sequences that showed the genetically intermixed. It also could be correlated with long-distance migration theory of $N$. lugens that migrate from tropical (northern Vietnam) in April-May to temperate region (China, Korea, and Japan) in (June-July) as demonstrated based on meteorological studies (Otuka et al. 2008). The $N$. lugens population is long-distance migratory flights from tropical to temperate Asia regions before modern pesticides were widely used on tropical rice. Because of the infrequent pre-1960s use of insecticides in the tropics, factors other than insecticides likely triggered the movement of long wings form populations of $N$. lugens (Bottrell and Schoenly 2012).

The homogeneity genetic diversity in N. lugens populations of Java might be maintained by extensive migration. The rice planthopper problem is occurred since the green revolution in 1960s in Indonesia; i.e. utilizing of later improved cultivars and pesticides (IRRI 2009). Accordingly, we hope that the lack of genetic structure information of $N$. lugens could support the monitoring and tracing planthopper migration routes. The migration of the insect is confirming, than combine with findings on wing polymorphism (Iwanaga et al. 1987; Iwanaga and Tojo 1988) and biotype property of brown planthopper (Sogawa 1982). Thus the new controlling strategies based on forecasting systems could be developed for regional management of this insect.

\section{Acknowledgements}

The authors would like to thank CRDF Global for the research grant IDB1-80761-BO-14 entitled "Migration of Brown Planthopper in Java: insights from the Molecular Approach" on behalf of Dr. Rika 
Raffiudin, (Department of Biology, IPB University) in collaboration with Prof. Prema Arasu (Vice Provost and Associate Vice President of International Programs, Washington State University). We would also thank the USAID under "Smart Coalition for Agricultural Productivity in Indonesia", collaboration of Washington State University (WSU), IPB University (Bogor Agricultural University), and Indonesian Institute of Sciences (LIPI) for Ph.D scholarship to Ruth Martha Winnie during the year 2012-2015.

\section{References}

Beerli P, Felsenstein J. 2001. Maximum likelihood estimation of a migration matrix and effective population sizes in subpopulations by using a coalesent pproach. Proceed National Academy Sciences United States Americ 98:45-63.

Bohonak AJ. 2002. IBD (Isolation By Distance): a program for analyses of isolation by distance. J Heredity 93: 153-154

Bottrell DG, Schoenly KG. 2012. Resurrecting the ghost of green revolutions past: The brown planthopper as a recurring threat to high-yielding rice production in tropical Asia. J Asia-Pacific Entomol 15:122-140.

Chapuis et al. 2008. Do outbreaks affect genetic population structure? A worldwide survey in Locusta migratoria, a pest plagued by microsatellite null alleles. Molec Ecol 17:3640-3653.

Denno RF, Roderick GK. 1990. Population biology of planthoppers. Annu Rev Entomol 35:489-520.

Denno et al. 1991. Density-related migration in planthoppers (Homoptera: Delphacidae): The role of habitat persistence. Am Nat 138:1513-1541.

Dieringer D, Schlotterer C. 2003. Microsatellite analyzer (MSA): a platform independent analysis tool for large microsatellite data sets. Molec Ecol Notes 3:167-169.

Ersts PJ.2006. Geographic Distance Matrix Generator (version 1.2.3). American Museum of Natural History, Center for Biodiversity and Conservation. Available at: http:// biodi-versityinformatics.amnh.org/open_source/ gdmg. [Date accessed: 1 October 2015]

Excoffier L, Lischer HEL. 2010. Arlequin suite ver 3.5: a new series of programs to perform population genetics analyses under Linux and Windows. Molec Ecol Resources 10:564-567.

IRRI 2009. Planthoppers: new threats to the sustainability of intensive rice production systems in Asia. In: Heong KL, Hardy B (Eds.). Los Baños (Philippines): International Rice Research Institute. pp. 179-190.

Iwanaga K et al. 1987. Wing polymorphism in Japanese and foreign strains of the brown planthopper, Nilaparvata lugens. Entomol Experimentalists Applicata 43:3-11.

Iwanaga K, Tojo S. 1988. Comparatives studies on the sensitivities to nymphal density, photoperiod, and rice stage in two strains of the brown planthopper, Nilaparvata lugens Stal. (Homoptera: Delphacidae). Japanese J Applied Entomol Zool 32:68-74.

Jing et al. 2012. Isolation and characterization of microsatellite markers in brown planthopper (Nilaparvata lugens). Int J Mol Sci 13:9527-9533.
Kalinowski ST. 2009. How well do evolutionary trees describe genetic relationships among populations? J Heredity 102:506-513.

Kusmayadi et al. 1990. The spatial distribution pattern of the brown planthopper Nilaparvata lugens Stal. (Homoptera: Delphacidae) in West Java, Indonesia. Res Popul Ecol 32:67-83.

Matsumoto et al. 2013. Mitochondrial cox sequences of Nilaparvata lugens and Sogatella furcifera (Hemiptera, Delphacidae): low specificity among Asian planthopper populatins. Bull Entomol Research 4:1-11.

Mantel N. 1967. The detection of disease clustering and a generalized regression approach. Cancer research 27:209-220.

Otuka et al. 2008. A migration analysis for rice planthoppers, Sogatella furcifera (Horvath) and Nilaparvata lugens (Stal.) (Homoptera: Delphachidae), emigrating from northern Vienam from April to May. Appl Entomol Zool 43:527-534.

Raymond M, Rousset F. 1995. GENEPOP (version 1.2): population genetics software for exact tests and ecumenicist. J Heredity 86:248-249.

Rozas et al. 2003. DnaSP, DNA polymorphism analyses by the coalescent and other methods. Bioinformatics 19:2496-2947.

Sawada et al. 1992. Population dynamics of the brown planthopper in the coastal lowland of West Java, Indonesia. JARQ 26:88-97.

Sawada et al. 1993. Comparative analysis of population characteristics of the brown planthopper, Nilaparvata lugens Stal, between wet and dry rice cropping seasons in West Java, Indonesia. Res Popul Ecol 35:113-137.

Slatkin M. 1987. Gene flow and the geographic structure of natural populations. Science 236:787-792.

Sogawa K. 1982. The rice brown planthopper: feeding physiology and host plant interactions. Annual Review of Entomol 27:49-73.

Sogawa K. 1992. A change in biotype property of brown planthopper populations immigrating into Japan and their probable source areas. Proc Assoc Pl Prot Kyushu 28:63-68.

Sun et al. 2015. Evidence for high dispersal ability and mitonuclear discordance in the small brown planthopper, Laodelphax striatelluss. Scientific Reports 5:1-10.

Tamura et al. 2013. MEGA6: Molecular evolutionary genetics analysis version 6.0. Molec Biol Evol 30:2725-2729.

Thompson et al. 1997. The clustal X windows interface: flexible strategies for multiple sequence alignment aided by quality analysis tools. Nucl Acid Res 24:48764882.

van Oosterhout et al. 2004. Micro-checker: software for identifying and correcting genotyping errors in microsatellite data. Molec Ecol Notes 4:535-538.

Wei et al. 2013. Genetic structure and demographic history reveal migration of the Diamondback Moth Plutella xylostella (Lepidoptera: Plutellidae) from the Southern to Northern Regions of China. Plos One 8:1-14.

Zhang et al. 2013. The complete mitochondrial genomes of two rice planthoppers, Nilaparvata lugens and Laodelphax striatellus: conserved genome rearrangement in Delphacidae and discovery of new characteristics of atp8 and tRNA genes. BMC Genomics 14:417-428. 